\title{
The Double in Roxana: the Primitive and the Uncanny*
}

\author{
Hye-Soo Lee \\ Konkuk University, Seoul, Korea
}

\begin{abstract}
I examine in this paper how Roxana explores the uncanny otherness of modern subjectivity, particularly through the figure of the double as a quintessential literary corollary of a narcissistic self whose problematic relation with oneself as well as the other is often represented in the form of the double. As an exquisite literary device that incarnates the repressed anxiety or fear of the self, which is often employed in Gothic or Romantic writings, the uncanny double works as a peculiar topos to belie and undermine the idea of modern subjectivity as an autonomous individual. Roxana deploys it with dexterity and power as a significant way to explore modern subjectivity. Amy largely plays the primitive double, while she also exhibits how the connotation of the double is historically altered. Susan as the uncanny double narcissism embodies Roxana's desire for a non-split self as well as self-fear, and her killing unavoidably leads to the suicidal destruction of Roxana herself.
\end{abstract}

Keywords: Daniel Defoe, Roxana, the double, the uncanny, self-division, modern subjectivity, narcissism

\section{Introduction}

Robinson Crusoe's spotting of “the print of a man's naked foot”on his desert island and his enormous fear of the possible other might be one of the most curious, enduring, and uncanny moments in the history of the early British novel. One reason for this uncanny feeling lies in that "the hidden self-other structure" of Robinson Crusoe, a "myth of singleness," is brought into the open (Brown, 1971, p. 571). Defoe's first singular novel is predicated on the self's fear of the other whether the other materializes in the form of a cannibal or exists within himself as intolerable anxiety of hidden enemies. A man's "footprint" is an inscrutable yet potent sign that reveals the threatening otherness in and out of the self. In his last novel, Roxana, the footprint comes to life in the form of a real person, Susan, who pursues Roxana her mother with a tenacious demand for recognition as daughter. Like the footprint seen by Crusoe, Susan's abrupt appearance at the end of the novel and her relentless quest for her mother extraordinarily perturb Roxana's apparently reformed life. Yet while Crusoe manages to master the fear by the domestication of a native cannibal naming him Friday, Roxana feels herself constrained to kill her namesake daughter, who refuses to be under her control, though the actual deed is done by Amy her bizarrely loyal maid. Moreover, Crusoe returns to a unified and stable self despite a recurring suspicion of it, but Roxana is unable to recover from the repercussion of her daughter's death but is haunted by her who "was ever before [her] Eyes...by-Night, and by-Day...with her Throat cut” and eventually “[falls] into a dreadful Course of Calamities” with "Amy also" (Defoe, 1724, pp. 325, 329). As is implied in both her weirdly persistent pursuit of her mother

\footnotetext{
* Acknowledgements: This work was supported by the National Research Foundation of Korea Grant funded by the Korean Government (NRF-2014S1A2A1A01026860). Hye-Soo Lee, Associate Professor, Department of English, Konkuk University.
} 
and the mother's inordinate fear and desperate flight from her, Susan stands as "the double" of Roxana. As the uncanny double, she embodies Roxana's repressed fear of herself, hidden yet familiar, as well as her desire for an integral self; or, she personifies the ultimate predicament of self-division in a modern self. Long before the double motif is employed in gothic novelsor writings of Romanticism from the late eighteenth century, Defoe deployed it in Roxana with dexterity and power as a significant way to explore modern subjectivity.

In this paper, I examine how Roxana explores the uncanny otherness of modern subjectivity, particularly through the figure of "the double" as a quintessential literary corollary of a modern narcissistic self whose problematic relation with oneself as well as the other is often represented in the form of the double in modern literature. Discussions of the double are not new in Roxanacriticism, though they are usually limited to an account of Amy and that analyses of the double in Roxana in terms of "the uncanny" are scattered. As Leo Braudy (1973) notes, the figure of the double in a broad sense is a reiterating motif in Defoe's novels if we consider Friday or Mother Nightas the double of Crusoe or Moll, respectively. Indeed, the double in this sense works as one key with which to enter Defoe's novelistic world since it illustrates the "radical egocentricity" or "radical individualism" of Defoe's novels; few minor characters stand as the self, or hold "an individualized other consciousness confronting the protagonist," but remain merely as the colonized other (Brown, 1971, pp. 565, 577, 567). In Roxana, however, the double figure emerges not only as a good faithful helper whose raison d'être is to serve the hero/ine, but also as a haunting nightmare to disturb and decenter the self-absorbed ego. As we will see later, if Amy foremost exists as "the primitive double" of Roxana in the first sense, though she is more complicated than that in evincing the historical transformation of the meaning of the double, Susan stands as "the uncanny double" in the second sense, surreally revealing the inner psychological conflicts in the self.

It is notable here that the double in the sense of an epitome of the uncanny is mostly a modern phenomenon in a crucial sense. As an exquisite literary device that incarnates the repressed anxiety of the self, which is often employed in the investigation of the split self in Romantic writings or gothic novels, the uncanny double works as a peculiar way to belie or undermine the ideal of modern subjectivity as an autonomous individual. Or, it is recognition, though reluctantly, that our modern self is not a stable, fixed, or unitary one but is constituted by divided and decentered selves. Roxana displays this uncanny kind of the double ingeniously, making a profound though ambiguous comment on the perplexing self-division of modern subjectivity. Thus the coexistence of decentered modern subjectivity and radical modern individualism in Roxana, despite apparent contradiction, is not so much a puzzling enigma but a crucial and symptomatic facet of modernity. Terry Castle (1996) remarks in her reading of Sigmund Freud's "The Uncanny" how his "vital insight” suggests a way to resolve the ostensible contradiction between "the irrational and gothic side of eighteenth-century culture" and "classic Enlightenment rationalism," a bewildering phenomenon to many scholars of the eighteenth-century studies (pp. 6-7). As Freud (1957) argues, the uncanny, a recurring morbid anxiety that originates from "something which is familiar and old-established in the mind and which has become alienated from it only through the process of repression," depends on "rationalization" that represses mysterious primitive belief and covert infantile complexes (p. 241). In other words, the eerie and creepy feeling of the uncanny is a product of the historical process of rationalization around the eighteenth century, or "the eighteenth century in a sense 'invented the uncanny"'(Castle, 1996, p. 8). Considering the historical conjunction of the Enlightenment rationalism and the emergence of the uncanny in the eighteenth century, it might not be as paradoxical as it first seems that the last novel of Defoe, an archetypical 
author of "modern individualism" and "formal realism" to Ian Watt (1957), for instance, turns to the uncanny double as a way to explore the self-division of the modern individual and the grotesque aesthetics involved. An inchoate sign of the uncanny double, or "a glimmer of that suspicion of the concept of the unified and identifiable 'subject”' (Brown, 1971, p. 583) is already found in Robinson Crusoe, but it is not until Roxana that Defoe confronts the decenteredness of the modern self through the figure of the double and the aesthetic of the uncanny.

Significantly, the figure of the double holds a strong and essential affinity with narcissism, as Otto Rank (1989) underlines in his pioneering and significant study The Double. For primary narcissism invokes the double in an original form as a wish fulfillment of "omnipotence thinking," while the uncanny double emerges and plagues the pathologically narcissistic self as a projection of that individual's repressed anxiety, fear, or, importantly, desire as Freud argues. In the following parts, I first take a look at how Amy plays the double of primary narcissism, principally working as "an angel guardian," yet how she also exists as a domesticated and colonized other associated with pathological narcissism. In the process, I discuss how this seeming paradox is related to the historical modification in the connotation of the double. In the second part, I explore the significance of Susan as the uncanny double that embodies Roxana's longing for a non-split and integral identity as well as her fear of her own self, and consider how the killing of the double unavoidably leads to the suicidal destruction of the self in Roxana as in most stories of the double.

\section{Amy as the Primitive Double}

Amy, "a cunning Wench” who is faithful to [Roxana] as the Skin to [her] Back” (Defoe, 1724, p. 25), not only stands as one of two intriguing doubles of Roxana but also enables the reader to ask a metafictional question of what the double, which is hardly subject to rational explanations, signifies in a realist novel like Roxana. As the first double of Roxana, Amy is distinct from the other and more potent double, Susan, largely in that she is foremost a product of Roxana's primary narcissism, a consequence of the omnipotence of thought, like instantaneous wish-fulfillments. As Rank points out, the double is "originally created as a wish-defense against a dreaded eternal destruction” (p. 86), i.e. from the fear of death or wish for immortality, and is intricately linked with primary narcissism in children and primitive man in its origin. Emerging as a loyal friend, or amie, in time of trouble, Amy plays a role of guardian angel, an original form of the double. Just as a child in serious trouble calls forth an imaginary friend in the child's wishful omnipotence thinking, Roxana in a traumatic situation conjures Amy, who would not leave her no matter what and takes care of all kinds of dirty practical things for her, when she "was despis'd by all [her] Relations" and "left so entirely desolate, friendless, and helpless" (Defoe, 1724, p. 74) after her husband left her moneyless. Once invoked, Amy not only helps Roxana survive the initial deathly crisis but also supports her to lead a flourishing life behind her back with her cunning and diligence; Roxana's strenuous struggle for and reaching out autonomy is basically predicated on Amy's devotion. Furthermore, as a single exception deviating from the narcissistic pattern of Roxana's relationship, Amy functions as the only other person that she could depend on without disguise or theatricality whenever she is materially needful, morally insecure, emotionally blue, or bodily lonely.

Significantly, however, Amy also shows how the idea of the double has been historically transformed from "an assurance of immortality" of primary narcissism into "the uncanny harbinger of death" of pathological narcissism, though she reverts to the naïve primitive double after the uncanny moment of the bedchamber scene 
(Freud, 1957, p. 235). Freud points out "the surprising evolution of the idea" of the double, referring to Rank's theory of the double, and explains how the anthropological signification of the double has been altered from "an insurance against the destruction of the ego" into an uncanny sign that indicates upcoming death (p. 235). As he implies in an observation that "the 'double' has become a thing of terror, just as, after the collapse of their religion, the gods turned into demons," the modification of the meaning of the double is deeply associated with the process of secularization or rationalization in modernity (Freud, 1957, p.236). With the advent of modernity, a human being, who has believed in the supernatural and sacred, should accept the rational and secular order of the scientific world, just as children should abandon their primary narcissism when they grow up. Likewise, the realm of the double, which used to be the space of the supernatural, has been changed into the area of the uncanny as the site of the return of the repressed in modern times.

Curiously, Freud (1957) indicates that many uncanny phenomena in reality hardly feel scary when they are represented in fairy tales, in whose logic children and primitive man's primary narcissism is not prohibited, though "the situation is altered as soon as the writer pretends to move in the world of common reality" (p. 250), i.e., in a modern genre like the novel. Amy as the double of primary narcissism may look natural in a fairy tale, but she cannot but be problematic in the novel like Roxana. For even though the reader senses that Amy works as the double of Roxana, as far as she moves as a maid bound to her mistress in a detailed realist setting, or "particular time and place”(Watt, 1957, p. 21), the reader cannot entirely ignore the narrative level that Amy does not stand as her own self but as a used, domesticated, or colonized other. However intimate they are, Amy structurally exists as "the other" to Roxana "the self," who could manipulate her loyal maid for her interest to the extent of making her a whore; their relationship is fundamentally unbalanced and one-sided in a real world. Thus though Amy is initially conjured as a protector of the self, or the double of primary and normal narcissism, she does not stay as guardian angel but soon takes a tint of the double of pathological narcissism, or "a thing of terror," though temporarily.

The bedchamber scene, in which Roxana thrust Amy into the bed of the landlord her unwedded husband, is a pivotal moment that Amy the naïve, primitive double also hovers as the uncanny one. In this scene, while Roxana attempts to forcibly dominate the given situation, what she sees "before [her] Face...[standing]-by all the while” (Defoe, 1724, p. 47) is not only Amy the subdued other but also herself re-enacting the role of a whore through her double. Or, Amy's "gaze" at her mistress makes Roxana inevitably decentered and the scene undeniably uncanny, though her counter look at her mistress from the bed is not directly described. "Gaze” as distinct from "look" is a representative instigator of the uncanny feeling since the gaze from the object or the other uncannily reveals the subject's repressed anxiety hidden yet familiar. The uncanny effect of the scene consists in that even when Roxana looks at Amy as the other to be capitalized on, she also sees herself in her maid through the gaze of her, who knows. Roxana's dread of the eye of the witness derives from her knowledge that the other knows - knows that she is essentially a worthless and inferior person, a "whore" in her term, in spite of apparent normality. Amy's supposed gaze reveals Roxana's deeply-rooted abhorred self-image, and fixes the scene as a notable moment of the uncanny. Faithful to "the surprising evolution of the idea" of the double, Amy, who is initially invoked as the double of primary narcissism, shifts into a vision of terror, though she soon reverts to the role of the double-helper, or an incredibly devoted assistant. 


\section{Susan as the Uncanny Double}

If Amy is conjured by Roxana as the primitive double to satisfy her primary narcissism, Susan stands as the uncanny double that emerges as the consequence of the history of her narcissistic self-division. Roxana could survive and gain worldly success through her mobile and performative self, which is predicated on the division of the seemingly flourishing public self and the private abominated self. But Roxana's self-division eventually works as "a terrible machine of self-torture" though it facilitates her apparently free and mobile life with little psychological bifurcation for quite a while (Maddox, 1984, p. 672). So when she realizes that she is not as young and beautiful as she was after a period of a kept mistress of the English king, Roxana finds herself repeatedly asking, "What am I a Whore for now?” (Defoe, 1724, p. 203): a moment of self-doubt and emptiness that debilitate a modern narcissist's essentially divided yet phenomenally contained self. She now talks uneasily about "the Concern I had upon me for my Children" (p. 203) and decides to reform herself into a decent mother in order to show up to her children, though she was usually indifferent or cold-blooded to them, notoriously saying, for instance, "I wou'd willingly have given ten Thousand Pounds of my Money, to have been rid of the Burthen I had in my Belly” (Defoe, 1724, p. 163). Susan’s entrance, however, revokes her plan to present herself as a proper mother and exposes the insufficiency of her performative self in the role of the mother. In contrast to other personas that she successfully adopted, the role of the mother cannot be effectively performed with movement or disguise, at least ifthe daughter (or son) demands a whole being instead of a public masked part from the mother. Roxana was able to rely on Amy as her surrogate mother to whom she could reveal her inmost private feelings and turn to for every practical need, but she now needs to be a mother herself in front of her daughter, who persistently demands her to acknowledge that she is her mother and that she is Roxana from Pall Mall.

Susan, "the busie impertinent Girl” who "haunted [her] like an Evil Spirit” (Defoe, 1724, pp. 299, 310), stands as the uncanny double that is projectively produced by Roxana's fear about herself and also her desire to reclaim an integrated self. Critics have justly focused on the issue of Roxana's irrational fear of her daughter, noting that Susan does not pose any practical threat to Roxana. There seem to be two closely related reasons that Roxana dreads Susan in such an extreme degree. First, Susan demands her mother something that she is unable to give, an embrace of relationship for relationship itself (or can we say love?). As William Warner (1998) remarks, Susan "articulates her self as an end in itself...in wanting nothing from Roxana but recognition as her daughter" (p. 171), and it almost kills Roxana, who adopts a defensive mechanism of self-splitting and wants to relate to her daughter only with that part of external grandiose self, to respond to her daughter's demand for relationship. In other words, Susan's claim for recognition as daughter amounts to an insurmountable challenge to Roxana since it requires her to integrate the ostensibly pretentious self and the secretly disdained self.

Secondly, Susan's position as “witness,"“spectator,” or "spy,” who has known Roxana as Roxana from the days of Pall Mall, makes her an enormously threatening figure to her mother. We have seen in the bedchamber scene how a witness, or a gaze from the other, signifies a horrible menace to Roxana. Just as Crusoe is swept away with fear of the imagined other that might have been watching him at the footprint, Roxana cannot help but dread Susan since her daughter watched her, or she was exposed to the gaze of her daughter, while she herself did not know she has been watched. Accordingly, Susan grows into an object of fear, whether she intends it or not, and becomes her mother's self-punishment. But Susan’s knowledge, such as "no, no, Madam...I know that; I 
know my Lady's Name and Family very well; Roxana was not her Name, that's true indeed" (Defoe, 1724, p. 289), is nothing but Roxana's own self-knowledge, the worthlessness of her genuine self of the name of Susan, after which her daughter is named. As a matter of fact, the fear of the other is interrelated with the fear of oneself at a fundamental level. The figure of the uncanny double as a metaphoric merger of the other and the self is a literary device that embodies one's dread of oneself, or one's unconscious self-awareness that is displaced and projected onto the uncanny other. Rank indicates that one's fear about oneself as strong as to be paranoid often results in the advent of the uncanny double: "the defensive form of the pathological fear of one's self often lead[s] to paranoid insanity and appear[s] personified in the pursuing shadow, mirror image or double” (pp. 85-86). Thus the nightmarish and surreal atmosphere in the last part of Roxana, which anticipates the last pursuit scene between Frankenstein and the Creature in Frankenstein among others, largely stems from Roxana's extreme fear of herself only in the form of the double's blind pursuit of her. Susan uncannily exposes Roxana's fear of herself, including her guilty feeling, while she also evidences that Roxana's achievement of modern autonomous self, which is principally grounded in her narcissistic self-division, is eventually perfunctory and unenduring: a catastrophic revelation that Roxana's fantasy of the free and mobile self is a lie.

The murder of Susan, a decisive yet long repressed event in the whole narrative, amounts to Roxana's desperate yet vain gesture to restore her contained performative self by stifling a moment of illumination brought by her encounter with the uncanny double. Crusoe could reconstitute his unified self through what David Marshall (2004) calls “autobiographical acts" despite recurring moments of instability provoked by his encounter with the other, such as the footprint, the parrot calling his name, or the old dying goat in the cave. Like Crusoe, Roxana seems to almost succeed in repossessing her established self after Susan's death: she manages to re-enact her initial plan to play a role of good mother to her other remaining daughter; she departs to Holland as a newly wedded wife of the Dutch merchant as if nothing happened and is there honored to be called "the Countess de ----.” Unlike Crusoe's footprint, an uncanny sign to be interpreted, however, Susan the double does not so easily go away but haunts her mother endlessly, even after she is killed, precisely because she is the double of Roxana, however tautological it sounds. The death of Susan signifies nothing else than the destruction of Roxana herself for "the frequent slaying of the double, through which the hero seeks to protect himself permanently from the pursuits of his self, is really a suicidal act” (Rank, 1989, p. 79). The last paragraph abruptly and drily informs the reader that Roxana "fell into a dreadful Course of Calamities, and Amy also...the Blast of Heaven seem'd to follow the Injury done to the poor Girl, by us both” (Defoe, 1724, p. 329).

\section{Conclusion}

Roxana cannot get away from the repercussions ensuing from the murder of Susan since slaying the double partly means the stifling of the self's desire or will to live. The uncanny double is a personified projection not only of the self's ingrained fear about oneself but also of one's longing for an integrated self or a reconciliation with one's past history. The famous scene where Roxana feels “a secret inconceivable Pleasure” while kissing Susan even among extreme "secret Horror" (Defoe, 1724, p. 277) in a ship for Rotterdam vividly illustrates how desperately and unconsciously the mother longs to reach out to her daughter as much as she dreads her. Roxana's irresistible outpouring of affections for her daughter corroborates how Susan epitomizes her desire to (re)gain her integrated self, if ever, as much as her fear of her own covert worthlessness. Holding her mother's private and real 
name, Susan embodies not only her inmost fear but her unfulfilled desire. By killing Susan, Roxana loses a chance to reshuffle and integrate her self-division through an uncanny encounter with the double.

Furthermore, there remains another troubling irony in the elimination of Susan from Roxana's life and the text. Amy, who carries out the killing of Susan with the mute assent of Roxana, never knows that Susan's death ultimately implies the annihilation of her mistress as well as the removal of her destressing woes. Even though she could do everything for Roxana as a guardian angel or a pampering mom, she hardly knows, unlike Susan, and her knowledge, if any, cannot but be narrow and restrained. For she basically exists as the double of primary narcissism that satisfies a child's omnipotence thinking as in a fairy tale, and in consequence is unable to address the problem of the self's repressed desire or fear represented in a realist text. While Amy becomes an active and controlling agent more and more and becomes "all the Relief [Roxana] had" in her whole life, she cannot fill her mistress' fundamental "Hole in [her] Heart," or her feeling of emptiness as an inevitable consequence of narcissistic self-division even by killing Susan (Defoe, 1724, pp. 281, 264). As much as she destroys Susan, however, her un-reality is ambiguously and abortively disclosed by the other powerful uncanny double with the same name of her mistress. Straddled between an impulse for realistic representation and the radical and skillful employment of the double figure, Defoe's last novel ends with the sad face and bitter heart of a modern narcissistic self.

\section{References}

Braudy, L. (1973). Daniel Defoe and the anxieties of autobiography. Genre, 6.

Brown, H. (1971). The displaced self in the novels of Daniel Defoe. ELH, 38(4), 562-590.

Castle, T. (1996). The female thermometer: Eighteenth-century culture and the invention of the uncanny. Oxford: Oxford University Press.

Defoe, D. (1724). Roxana. Oxford: Oxford University Press, reprinted in 1998.

Freud, S. (1957). The uncanny. The standard edition of the complete psychological works of Sigmund Freud (J. Strachey, Trans.). London: The Hogarth Press.

Maddox, J. (1984). On Defoe’s Roxana. ELH, 51(4), 669-691.

Marshall, D. (1986). The figure of theater: Shaftesbury, Defoe, Adam Smith, and George Eliot. New York: Columbia University Press.

Marshall, D. (2004). Autobiographical acts in Robinson Crusoe. ELH, 71(4), 899-920.

Rank, O. (1989). The double. H. Tucker, Jr, (Ed.) (Trans.). London: Maresfield Library.

Warner, W. (1998). Licensing entertainment: The elevation of novel reading in Britain, 1684-1750. Berkeley: University of California Press.

Watt, I. (1957). The rise of the novel: Studies in Defoe, Richardson, and Fielding. Berkeley: University of California Press, reprinted in 2000 . 